\title{
ESTRUTURA GENÉTICA EM MICROESCALA ESPACIAL DE Myrcia splendens

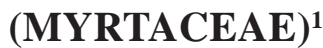

\begin{abstract}
Murilo Malveira Brandão², Fábio de Almeida Vieira ${ }^{3}$ e Dulcinéia de Carvalho ${ }^{4}$
RESUMO - Em ecossistemas fragmentados, comuns no sul de Minas Gerais, os corredores de vegetação são elementos de grande importância ecológica para o fluxo gênico. Os corredores de vegetação na região de Lavras, MG, são estreitos (entre 3 e 6m), de vegetação secundária formada pela colonização de valas e interligam fragmentos remanescentes de vegetação primária. Nestes dois ambientes, é comum a ocorrência da espécie Myrcia splendens, que produz frutos de dispersão zoocórica. Objetivou-se, neste trabalho, a avaliação da estrutura genética espacial em microescala de $M$. splendens nos ambientes de fragmentos e nas suas conexões. Dez primers ISSR foram utilizados em 168 árvores distribuídas nos cinco fragmentos e em 104 árvores nos quatro corredores de vegetação, gerando um total de 70 locos polimórficos. A AMOVA mostrou que a maior parte da diversidade genética ocorre dentro das populações (96,49\% nos fragmentos e 91,15\% nos corredores). Nas formações primárias (F1 a F5) e nos corredores C1 e C2 os genótipos estão distribuídos de maneira aleatória. Nos corredores C3 e C4 observou-se estruturação genética espacial, com valores de coancestria positiva e significativa na primeira classe de distância, sendo os valores de $S p$ de $0,012(P=0,009)$ e 0,014 $(P=0,029)$, respectivamente.
\end{abstract}

Palavras-chave: Coancestria, Diversidade genética e Espécie arbórea.

\section{FINE-SCALE GENETIC STRUCTURE OF Myrcia splendens (MYRTACEAE)}

\begin{abstract}
In fragmented ecosystems, very common in southern Minas Gerais, vegetation corridors are ecologically important elements for gene flow. Vegetation corridors in Lavras, MG, are narrow (from 3 to $6 \mathrm{~m}$ ), with secondary vegetation formed by trench colonization and they connect primary vegetation fragments. In both environments, it is common the occurrence of Myrcia splendens, which produces fruit with zoocoric dispersion. The objective of this work was to evaluate spatial genetic structure in fine-scale of Myrcia splendens (SW.) in environments with fragments and in their connections. Ten ISSR primers were used to access the genetic patterns in 168 trees distributed in five fragments and in 104 trees distributed in four vegetation corridors, totalizing 70 polymorphic loci. AMOVA revealed that most of the genetic diversities occurs within the the populations ( $96.49 \%$ in the fragments and $91.15 \%$ in the corridors). In the primary formations (F1 to F5) and in the corridors C1 and C2, the genotypes are randomly distributed. It was noted in C3 and C4 corridors, spatial genetic structure with positive and significant coancestry in the first distance class with $S p=0.012$ $(P=0.009)$ and $0.014(P=0.029)$, respectively.
\end{abstract}

Keywords: Coancestry, Genetic diversity and Tree species.

\footnotetext{
${ }^{1}$ Recebido em 18.02.2009 e aceito para publicação em 02.05.2011.

${ }^{2}$ Programa de Pós-Graduação em EcologiaAplicada-UniversidadeFederal deLavras, UFLA, Brasil.E-mail: <murilomalveira@yahoo.com.br>.

${ }^{3}$ Universidade Federal do Rio Grande do Norte, UFRN, Brasil. E-mail: < vieirafa@ufrnet.br>.

${ }^{4}$ Universidade Federal de Lavras, UFLA, Brasil. E-mail: <dulce@dcf.ufla.br>.
} 


\section{INTRODUÇÃO}

A Floresta Estacional Semidecidual é uma fitofisionomia característica de grande parte de Minas Gerais, apresentando alta diversidade florística. A rápida devastação dessas florestas alterou seus ecossistemas primários, confinando-os em áreas protegidas ou em locais inadequados para a agricultura, resultando em remanescentes florestais. Essa fragmentação da paisagem tem efeitos em processos ecológicos (COUVET, 2002) e genéticos (LOWE et al., 2005). Portanto, a conexão de fragmentos por corredores de vegetação é um importante elemento mitigador dos efeitos negativos da fragmentação (KIRCHNER et al., 2003; VIEIRA; CARVALHO, 2008).

A paisagem do sul de Minas Gerais é caracterizada pela presença de pequenos fragmentos florestais, circundados por pastagem e cultivo de milho ou café. Esses fragmentos são conectados por corredores de vegetação secundária, originados da colonização de valas. O conhecimento e o entendimento da diversidade genética e estrutura genética espacial em microescala são importantes para o manejo dos recursos genéticos florestais e também para avaliar os impactos da exploração e fragmentação e estabelecer estratégias de amostragem em populações naturais (MORAES et al., 2005; SOUZA et al., 2007).

A diversidade genética de populações naturais de plantas tem sido quantificada por marcadores moleculares como ISSR (GE et al., 2005; MELONI et al., 2006; KUMAR et al., 2010). Marcadores ISSR (Inter Simple Sequence Repeats) são dominantes, desenvolvidos por Zietjiewicz et al. (1994), e não requerem informações prévias de sequências de DNA da espéciealvo. Em comparação com outros marcadores baseados em PCR não específicos, como RAPD (Random Amplified Polymorphic DNA), ISSR produzem fragmentos com grande reprodutibilidade e baixo custo de operação. A técnica de ISSR utiliza primers baseados em SSR (microssatélite) ancorado na extremidade 5' ou 3' da sequência, com 2 a 4 bases de purina ou pirimidina.

No sistema de fragmentos-corredores do Município de Lavras (MG), é comum a espécie Myrcia splendens (SW.) DC. (Myrtaceae), principalmente nas bordas dos fragmentos. Sua ocorrência vai desde o México até o sul do Brasil e, segundo Oliveira-Filho (2006), algumas sinonímias são $M$. acutata DC., M. rostrata DC., M. communis Berg e M. fallax (Rich.) DC. Myrcia splendens foi escolhida para este estudo, devido à sua ocorrência em todos os corredores e fragmentos analisados, sendo considerada uma espécie modelo para futuras comparações com espécies de vida semelhante. A espécie é polinizada por abelhas e dispersão zoocórica (GRESSLER et al., 2006).

Este trabalho teve como objetivos caracterizar os padrões da variabilidade genética dentro e entre populações e a estrutura genética em microescala espacial de Myrcia splendens, em cinco fragmentos e quatro corredores de vegetação, a partir de dados gerados pelos marcadores moleculares ISSR.

\section{MATERIAL E MÉTODOS}

\subsection{Local de estudo e amostragem}

O local do estudo situa-se no município de Lavras, sul de Minas Gerais (Figura 1) entre as coordenadas

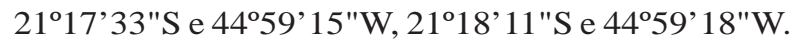
Os fragmentos de floresta semidecidual possuem de 1 a 11,8 ha e são conectados por corredores de vegetação secundária, com largura de 3 a 6 m e extensão variando de $367 \mathrm{~m}$ a $1039 \mathrm{~m}$. Todas as árvores reprodutivas de M. splendens foram amostradas e georreferenciadas espacialmente por meio do Sistema de Posicionamento

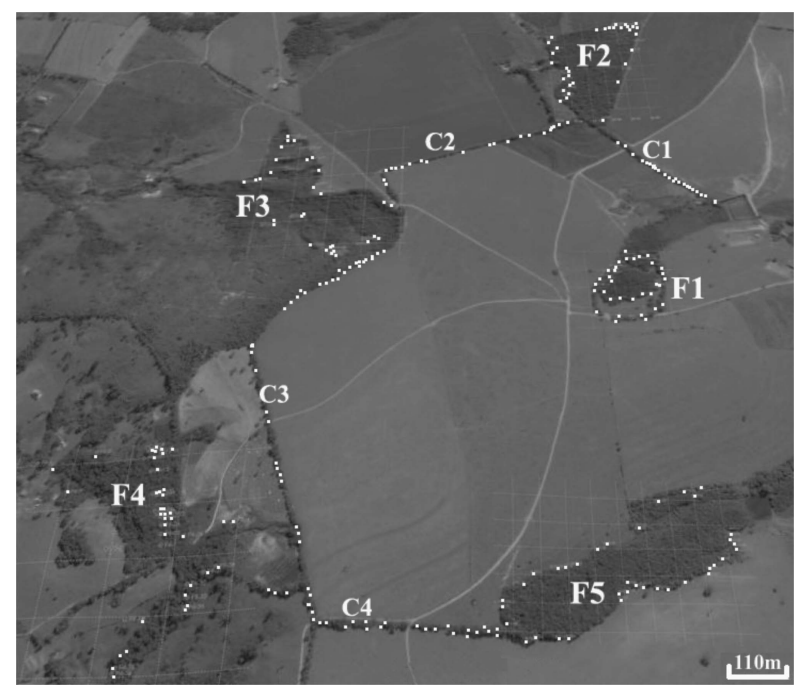

Figura 1 - Posição e distribuição espacial de árvores de Myrcia splendens (pontos em branco) em fragmentos (F1 a F5) e corredores (C1 a C4) na região do Alto Rio Grande, em Lavras, sul de Minas Gerais.

Figure 1 - Position and spatial distribution of Myrcia splendens trees (points in white) in fragments (F1 to F5) and corridors (C1 to C4) in Alto Rio Grande, Lavras, southern Minas Gerais. 
Global (GPS), sendo 168 árvores nos fragmentos e 104 nos corredores. Amostras foliares de cada árvore foram identificadas e acondicionadas em gelo. As amostras foram armazenadas em deep freezer até o momento da extração do DNA.

\subsection{Extração do DNA e eletroforese}

A extração do DNA foi realizada pelo método CTAB (cetyltrimethylammonium bromide) com $0,2 \%$ de $\beta$ mercaptanol, utilizando $200 \mathrm{mg}$ de folhas, seguida da extração com clorofórmio e álcool isoamílico. Amostras do DNA de cada árvore foram amplificadas pela técnica de PCR (Polymerase chain reaction), utilizando-se primers ISSR. Para a reação de PCR, foi utilizado o volume total de $12 \mu \mathrm{l}$, sendo $2 \mu \mathrm{l}$ de DNA diluídos, e $10 \mu \mathrm{l}$ do coquetel de reação contendo 1,2 $\mu$ l de tampão PCR 10X (500mM Tris-HCl pH 8,0; 200mM KCl; 2,5 mg.mL-1 BSA; 200mM Tartrazine e 1\% Ficoll), 1,04 $\mu \mathrm{l}$ dNTP $+\mathrm{MgCl}_{2}(\mathrm{dNTP}$ a 2,5mM; $\quad \mathrm{MgCl}_{2}$ a $25 \mathrm{mM}$ ), $0,96 \mu$ l de diluente da enzima Taq polimerase, $0,3 \mu \mathrm{l}$ Taq polimerase (5u. $\left.\mu \mathrm{l}^{-1}\right)$ e $2 \mu \mathrm{l}$ primer ISSR $(2 \mu \mathrm{M})$, e completado o volume com água ultrapura. O programa de amplificação foi de 37 ciclos de 1 minuto a $94{ }^{\circ} \mathrm{C}$, $47^{\circ} \mathrm{C}$ por 2 minutos e $72{ }^{\circ} \mathrm{C}$ por 2 minutos. A análise dos produtos da reação foi realizada em géis de agarose $1,5 \%$, corados com brometo de etídio e submetidos a uma voltagem de $120 \mathrm{~V}$ por $2 \mathrm{~h} 30 \mathrm{~min}$. Para o controle de pureza dos componentes do coquetel, foram incluídas amostras sem DNA (controle negativo) em cada reação.

\subsection{Análise dos dados}

A partir das análises das fotografias dos géis, os marcadores ISSR foram genotipados quanto à presença (1) e à ausência (0) das bandas, gerando uma matriz binária, utilizada para a divisão da variância entre seus componentes dentro e entre populações (níveis hierárquicos). A análise de variância molecular (AMOVA) foi realizada de acordo com Excoffier et al. (1992), com o auxílio do programa ARLEQUIN, versão 3.11 (EXCOFFIER et al., 2007). Assumindo que os indivíduos dentro das populações possuem o mesmo padrão de cruzamento, calculou-se a matriz de distância fenotípica para os pares de comparações, utilizando um coeficiente de similaridade genética. Para o cálculo da AMOVA, foi utilizado, como coeficiente, o quadrado das distâncias euclidianas, análogo às análises de Excoffier et al. (1992). A significância dos componentes da variância foi testada com 10.000 permutações.
Para a estrutura genética espacial (EGE), foi estimado o valor de coancestria pelo coeficiente kinship, entre os pares de indivíduos para as diferentes classes de distância (HARDY, 2003), com o uso do programa SPAGeDi, versão 1.2g (HARDY; VEKEMANS, 2002). Na análise, foi considerado coeficiente de endogamia igual a zero. $\mathrm{O}$ coeficiente kinship é dado por $\mathrm{F}_{\mathrm{ij}}=\left(\mathrm{Q}_{\mathrm{ij}}-\mathrm{Q}_{\mathrm{m}} / 1-\mathrm{Q}_{\mathrm{m}}\right)$, em que $F_{i j}$ é o coeficiente kinship de coancestria genética entre $i$ e $j$; $Q_{i j}$ é a probabilidade de as amostragens aleatórias de $i$ e $j$ serem idênticas por ascendência; $Q_{m}$ é a probabilidade média de que amostragem aleatória feita na população seja idêntica por ascendência.

O erro-padrão da média das estimativas foi obtido por reamostragem jackknife e, a partir dele, foram determinados os intervalos de confiança a $95 \%$ de probabilidade do coeficiente de coancestria médio estimado para cada classe de distância. A ausência de EGE foi testada dentro de cada classe de distância, utilizando-se 1.000 permutações (HARDY; VEKEMANS, 2002). A magnitude da EGE foi calculada usando a estatística $S p$ (VEKEMANS; HARDY, 2004): $S p=-b_{\text {log }} /\left(1-F_{i j(1)}\right)$, em que $b_{l o g}$ é a inclinação da curva de regressão do coeficiente de coancestria; $F_{i j(1)}$ é a média do coeficiente de coancestria da primeira classe de distância $\left(F_{i j}\right)$. Os valores $S p$ foram utilizados para comparar a extensão da estrutura genética espacial entre as populações.

\section{RESULTADOS}

Os 10 primers ISSR utilizados geraram 70 locos polimórficos (Tabela 1). A análise de variância molecular (AMOVA) indicou que a maior parte da diversidade genética de $M$. splendens encontra-se dentro das populações, tanto nos ambientes de vegetação primária (96,5\%) quanto nos ambientes de vegetação secundária (91,1\%), (Tabela 2).

Os resultados da estatística $S p$ mostram que não há estruturação genética $(P>0,05)$ nos fragmentos, portanto os genótipos apresentam distribuição aleatória (Tabela 3). Resultados semelhantes foram observados para os corredores C1 e C2. Os corredores C3 e C4 apresentaram estruturação genética na primeira classe de distância (Tabela 3 e Figura 2). O corredor de vegetação C3 apresentou valor de coancestria positiva $\operatorname{com} F_{i j}$ de $0,015(P=0,009)$ na primeira classe de distância $(70 \mathrm{~m})$, e no corredor C4 o valor de $F_{i j}$ foi de 0,050 $(P=0,029)$ também na primeira classe de distância $(27 \mathrm{~m})$. Analisando o sistema corredor de vegetação-fragmentos, observa-se que há estruturação genética, sendo $F_{i j}$ de 0,036 e significativo $(P=0,000)$ na primeira classe $(184 \mathrm{~m})$.

Revista Árvore, Viçosa-MG, v.35, n.5, p.957-964, 2011 
Tabela 1 - Primers utilizados, suas respectivas seqüências e número de bandas produzidas em Myrcia splendens.

Table 1 - Primers used in the experiment, their respective sequences and number of bands produced in Myrcia splendens.

\begin{tabular}{llc}
\hline Nome do primer & \multicolumn{1}{c}{ Sequência (5’'3’) } & Número de bandas \\
\hline AW3 (GT)6-RG & GTG TGT GTG TGT RG & 7 \\
BECKY (CA)7-YC & CAC ACA CAC ACA CAY C & 7 \\
CHRIS (CA)7-YG & CAC ACA CAC ACA CAY G & 11 \\
DAT (GA)7-RG & GAG AGA GAG AGA GAR G & 3 \\
GOOFY (GT) Y YG $_{\text {JOHN (AG)7-YC }}$ GTG TGT GTG TGT GTY G & 5 \\
M1 CAA-(GA)5 & AGA GAG AGA GAG AGY C & 7 \\
MANNY (CAC)4-RC & CAA GAG AGA GAG A & 7 \\
TERRY (GTG)4-RC & CAC CAC CAC CAC RC & 7 \\
UBC 843 (CT)8-RA & GTG GTG GTG GTG RC & 10 \\
\hline Total & CTC TCT CTC TCT CTC TRA & 6 \\
\hline
\end{tabular}

em que: $\mathrm{R}$ = purina (A ou $\mathrm{G})$ e $\mathrm{Y}$ = pirimidina $(\mathrm{C}$ ou $\mathrm{T}$ ).

Tabela 2 - Análise de variância molecular (AMOVA) de Myrcia splendens em cinco fragmentos de vegetação primária e quatro corredores de vegetação secundária.

Table 2 - Analysis of molecular variance (AMOVA) of Myrcia splendens in five fragments of primary vegetation and four corridors of secondary vegetation.

\begin{tabular}{llccc}
\hline Ambiente & Fonte de variação & Componentes da variância & Variação Total (\%) & $P$ \\
\hline \multirow{2}{*}{ Fragmentos } & Entre populações & 0,36 & 3,51 & $<0,0001$ \\
& Dentro de populações & 9,96 & 96,49 & $<0,0001$ \\
\hline \multirow{2}{*}{ Corredores } & Entre populações & 0,76 & 8,85 & $<0,0001$ \\
& Dentro de populações & 7,82 & 91,15 & $<0,0001$ \\
\hline Total (Frag.) & & 10,32 & 100 & \\
\hline Total (Cor.) & & 8,58 & 100 & \\
\hline$F_{\text {ST(Frag.) }}:$ & 0,035 & & & \\
$F_{\text {ST(Cor.) }}$ & 0,088 & &
\end{tabular}

Tabela 3 - Caracterização da estrutura espacial de Myrcia splendens nos cinco fragmentos, em quatro corredores de vegetação e nos corredores como um todo, incluindo para cada população o $n$ (número de indivíduos coletados), o coeficiente kinship $\left(F_{i j}\right)$ para primeira classe de distância, $B_{l o g}$, estatística $S p$ e valor de significância $(P)$.

Table 3 - Characterization of the spatial structure of Myrcia splendens in the five fragments, in four vegetation corridors and in the corridors as a whole, including for each population the $n$ (number of collected individuals), the coefficient kinship (Fij) for first distance class, $B_{\text {log }}$, statistics Sp and significance value (P).

\begin{tabular}{lcccc}
\hline Populações & $n$ & $F_{i j}$ & $B_{\log }$ & $S p$ \\
\hline Fragmento 1 & 33 & $-0,0031$ & $-0,0004$ & 0,0004 \\
Fragmento 2 & 31 & 0,0183 & $-0,0041$ & 0,0042 \\
Fragmento 3 & 30 & 0,0063 & $-0,0104$ & 0,0104 \\
Fragmento 4 & 38 & $-0,0040$ & $-0,0003$ & 0,0003 \\
Fragmento 5 & 36 & $-0,0106$ & $-0,0070$ & $0,126^{\mathrm{ns}}$ \\
Corredor 1 & 22 & 0,0017 & $-0,0024$ & 0,0069 \\
Corredor 2 & 21 & $-0,0019$ & $-0,0097$ & 0,0024 \\
Corredor 3 & 36 & 0,0150 & 0,0097 \\
Corredor 4 & 25 & 0,0502 & $-0,0123$ & $0,212^{\text {ns }}$ \\
Corredor total & 104 & 0,0364 & $-0,0140$ & $0,732^{\text {ns }}$ \\
\hline
\end{tabular}

Revista Árvore, Viçosa-MG, v.35, n.5, p.957-964, 2011 

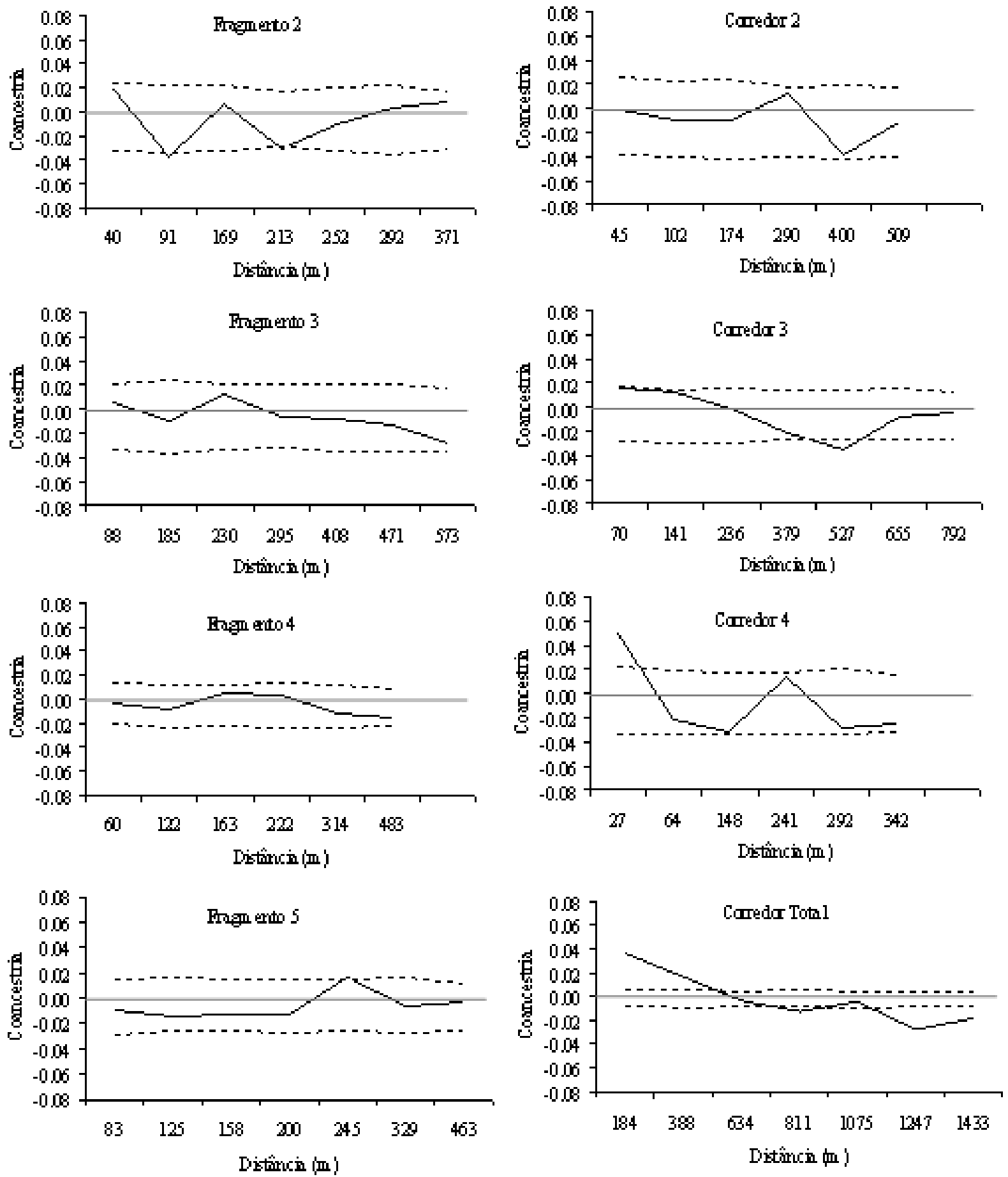

Figura 2 - Correlogramas do coeficiente de coanscetria de Myrcia splendens, por classes de distância, nos fragmentos e corredores de vegetação; ----- intervalo de confiança, a 95\% de probabilidade.

Figure 2 - Correlograms of coefficient of coanscetry of Myrcia splendens per distance classes, in the fragments and vegetation corridors; ----- confidence interval at 95\% of probability. 
Na análise de coancestria realizada somente nos corredores, os valores nas duas primeiras classes mostram que as árvores próximas são mais semelhantes entre si (Figura 2) com valores negativos e significativos $\left(F_{i j}=-0,020 ; P=0,000\right)$. A partir da sexta classe de distância em diante, as árvores são mais divergentes geneticamente em distância superior a 1.247 m (Figura 2).

\section{DISCUSSÃO}

\subsection{AMOVA}

Estimativas feitas com dados oriundos de marcadores moleculares dominantes, em populações de plantas que possuem fecundação cruzada, e calculadas pela AMOVA revelam que, em média, 28\% da divergência genética estão entre as populações (NYBOM; BARTISH, 2000). Os resultados de divergência genética obtidos em nosso estudo revelam que 3,5\% e 8,9\% encontram-se distribuídos entre os fragmentos e corredores, respectivamente. Esses dados são inferiores aos relatados por Nybom e Bartish (2000), mas estão em concordância com aqueles obtidos por Goulart et al. (2005) em Mabea fistulifera, espécie arbórea típica de borda de floresta semidecidual e Oliveira et al. (2008) em Dimorphandra mollis, espécie característica do Cerrado, onde 8,97\% e 10,3\% de divergência genética foram observadas entre as populações, respectivamente. No mesmo sistema de corredores-fragmentos aqui analisado, Vieira e Carvalho (2008) encontraram uma divergência genética de 3,0\% entre populações de Protium spruceanum.

Os resultados de variabilidade genética mostram que a maior proporção da variabilidade genética encontra-se dentro das populações (Fragmentos - 96,5\% e corredores $-91,1 \%$ ) e estão de acordo com os relatados para outras espécies arbóreas tropicais de fecundação cruzada e vida longa (LOVELESS; HAMRICK, 1984; WHITE et al., 1999; NYBOM, 2004; APTE et al., 2006). Os dados obtidos pela AMOVA podem ser devidos à proximidade dos fragmentos e pelo fato de estarem conectados pelos corredores de vegetação. A divergência entre populações é reduzida com o aumento do fluxo alélico, realizado via pólen e, ou, sementes. A polinização da $M$. splendens é entomofílica e a dispersão dos diásporos é zoocórica, realizada principalmente por pássaros, pequenos roedores e macacos (GRESSLER et al., 2006). Esses vetores provavelmente têm sua migração entre fragmentos facilitada pelos corredores de vegetação, o que resulta na baixa divergência genética entre os fragmentos.

Revista Árvore, Viçosa-MG, v.35, n.5, p.957-964, 2011

\subsection{Distribuição espacial}

Os resultados dos correlogramas (Figura 2) indicam a ocorrência de distribuição aleatória dos genótipos de $M$. splendens nos fragmentos, devido, possivelmente, ao suficiente fluxo alélico, evitando o agrupamento de indivíduos aparentados. Por outro lado, a estruturação genética detectada nos corredores indica a ocorrência de uma dispersão limitada de sementes no evento de colonização das valas, resultando em agregação dos genótipos das árvores.

A dispersão limitada de pólen e sementes tem sido reportada como a principal causa de estruturação genética espacial dentro de populações de plantas (LATTA et al., 1998; SMOUSE; PEAKALL, 1999). Em estudo realizado em microescala com a espécie Euterpe edulis no sul de Minas Gerais, Vieira et al. (2010) detectaram estruturação genética espacial dos genótipos, sendo esta atribuída à dispersão das sementes nas vizinhanças das árvores maternas.

As classes de distâncias representadas nos correlogramas (Figura 2), além de informação importante para o manejo, é uma indicação da distância mínima entre indivíduos amostrados para programas de melhoramento genético da espécie e para a coleta de sementes para programas de recuperação de áreas degradadas, de forma a obter maior variabilidade genética (KELLY et al., 2004; CLOUTIER et al., 2007). Portanto, os dados obtidos para M. splendens apontam que a distância de $70 \mathrm{~m}$ é a ideal para capturar maior variabilidade genética, evitando assim a coleta de sementes que possuem uma estrutura de famílias.

A média de $S p$ de 0,0068 obtida para $M$. splendens foi menor que os valores relatados para espécies com dispersão de sementes efetuada por animais $(S p=0,0088)$ (VEKEMANS; HARDY, 2004). Entretanto, este valor foi próximo ao encontrado para a espécie Sextonia rubra (Lauraceae) $(S p=0,006)$, que é uma espécie hermafrodita, com polinização por insetos e dispersão de sementes por pássaros (HARDY et al., 2006).

\section{CONCLUSÃO}

A maior parte da diversidade genética da espécie Myrcia splendens encontra-se dentro das populações. Nos fragmentos, não foi observada estruturação genética espacial, indicando que os genótipos de M. splendens estão distribuídos aleatoriamente. Nos corredores C1 e 
C2, os genótipos das árvores de $M$. splendens também se encontram distribuídos aleatoriamente. Nos corredores C3 e C4, M. splendens apresentou valores de coancestria positiva a $70 \mathrm{~m}$ e $20 \mathrm{~m}$, respectivamente, indicando que as árvores apresentam estrutura de família em curtas distâncias.

\section{AGRADECIMENTOS}

À Universidade Federal de Lavras, aos membros do Laboratório de Conservação Genética de Espécies Arbóreas (www.dcf.ufla/conservacao). À CAPES (Coordenação de Aperfeiçoamento de Pessoal de Nível Superior), pela concessão da bolsa de estudos. À FAPEMIG pelo apoio financeiro. Aos revisores anônimos, que contribuíram com sugestões valiosas para a melhoria do manuscrito.

\section{REFERÊNCIAS}

APTE, G. S. et al. Genetic diversity analysis in Gaultheria fragrantissima Wall. (Ericaceae) from the two biodiversity hotspots in India using ISSR markers. Current Science, v.91, n.12, p.16341640, 2006.

CLOUTIER, D. et al. Impact of selective logging on inbreeding and gene dispersal in an Amazonian tree population of Carapa guianensis Aubl. Molecular Ecology, v.16, n.4, p.797809, 2007.

COUVET, D. Deleterious effects of restricted gene flow in fragmented populations. Conservation Biology, v.16, n.2, p.369-376, 2002.

EXCOFFIER, L.; LAVAL, G.; SCHNEIDER, S. Arlequin: a software for population data analysis. Version 3.1. Geneva: University of Geneva, 2007. Disponível em: <http:// cmpg.unibe.ch/software/arlequin3>. Acesso em: 10 fev. de 2007.

EXCOFFIER, L.; SMOUSE, P. E.; QUATTRO, J. M. Analysis of molecular variance inferred from metric distances among DNA haplotypes: application to human mitochondrial DNA restriction data. Genetics, v.131, n.2, p.179-191, 1992.

GE, X. J. et al. Strong genetic differentiation of the East-Himalayan Megacodon stylophorus (Gentianaceae) detected by Inter-Simple Sequence Repeats (ISSR). Biodiversity and Conservation, v.14, n.2, p.849-861, 2005.
GOULART, M. F.; RIBEIRO, S. P.; LOVATO, M. B. Genetic, morphological and spatial characterization of two populations of Mabea fistulifera Mart. (Euphorbiaceae), in different successional stages. Brazilian Archives of Biology and Technology, v.48, n.2, p.275-284, 2005.

GRESSLER, E.; PIZO, M. A.; MORELLATO, L. P. C. Polinização e dispersão de sementes em Myrtaceae do Brasil. Revista Brasileira de Botânica, v.29, n.4, p.509-530, 2006.

HARDY, O. J. Estimation of pairwise relatedness between individuals and characterization of isolation by distance processes using dominant genetic markers. Molecular Ecology, v.12, p.1577-1588, 2003.

HARDY, O. J. et al. Fine-scale genetic structure and gene dispersal inferences in 10 Neotropical tree species. Molecular Ecology, v.15, p.559-571, 2006.

HARDY, O. J.; VEKEMANS, X. SPAGeDi: a versatile computer program to analyse spatial genetic structure at the individual or population levels. Molecular Ecology Notes, v.2, p.618-620, 2002.

KELLY, B. A.; HARDY, O. J.; BOUVET, J. Temporal and spatial genetic structure in Vitellaria paradoxa (shea tree) in an agroforestry system in southern Mali. Molecular Ecology, v.13, p.1231-1240, 2004.

KIRCHNER, F. et al. Role of corridors in plant dispersal: an example with the endangered Ranunculus nodiflorus. Conservation Biology, v.17, n.2, p.401-410, 2003.

KUMAR, S.; JENA, S. N.; NAIR, N. K. ISSR polymorphism in Indian wild orange (Citrus indica Tanaka, Rutaceae) and related wild species in North-east India. Scientia Horticulturae, v.123, n.3, p.350-359, 2010

LATTA, R. G. et al. Direct and indirect estimates of seed versus pollen movement within a population of ponderosa pine. Evolution, v.52, n.1, p.61-67, 1998.

Revista Árvore, Viçosa-MG, v.35, n.5, p.957-964, 2011 
LOVELESS, M. D.; HAMRICK, J. L.

Ecological determinants of genetic structure in plant populations. Annual Review of Ecology and Systematics, v.15, p.65-95, 1984.

LOWE, A. J. et al. Genetic resource impacts of habitat loss and degradation; reconciling empirical evidence and predicted theory for neotropical trees. Heredity, v.95, n.4, p.255-273, 2005.

MELONI, M. et al. Genetic variation in five mediterranean populations of Juniperus phoenicea as revealed by Inter-Simple Sequence Repeat (ISSR) markers. Annals of Botany, v.97, p.299-304, 2006.

MORAES, M. L. T.; KAGEYAMA, P. Y.; SEBBENN, A. M. Diversidade e estrutura genética espacial em duas populações de Myracrodruon urundeuva Fr. All. sob diferentes condições antrópicas. Revista Árvore, v.29, n.2, p.281-289, 2005.

NYBOM, H.; BARTISH, I. Effects of life history traits and sampling strategies on genetic diversity estimates obtained with RAPD markers in plants. Perspectives in Plant Ecology, Evolution and Systematics, v.3, n.1, p.93-114, 2000.

NYBOM, H. Comparison of different nuclear DNA markers for estimating intraspecific genetic diversity in plants. Molecular Ecology, v.13, p.1143-1155, 2004.

OLIVEIRA, D. A. et al. Variabilidade genética de populações de Fava D'anta (Dimorphandra mollis) da região Norte do Estado de Minas Gerais. Revista Árvore, v.32, n.2, p.355-363, 2008.
OLIVEIRA-FILHO, A. T. Catálogo das árvores nativas de Minas Gerais: mapeamento e inventário da flora nativa e dos reflorestamentos de Minas Gerais. Lavras: Universidade Federal de Lavras, 2006. 423p.

SMOUSE, P. E.; PEAKALL, R. Spatial autocorrelation analysis of individual multiallele and multilocus genetic structure. Heredity, v.82, n.5, p.561-573, 1999.

SOUZA, A. M. et al. Estrutura genética e espacial de populações naturais de Calophyllum brasiliense Camb. em mata de galeria. Cerne, v.13, n.3, p.239-247, 2007.

VEKEMANS, X.; HARDY, O. J. New insights from fine-scale spatial genetic structure analyses in plant populations. Molecular Ecology, v.13, p.921-935, 2004.

VIEIRA, F. A.; CARVALHO, D. Genetic structure of an insect-pollinated and bird-dispersed tropical tree in vegetation fragments and corridors: implications for conservation. Biodiversity and Conservation, v.17, n.10, p.2305-2321, 2008.

VIEIRA, F. A. et al. Spatial pattern and fine-scale genetic structure indicating ecent colonization of the palm Euterpe edulis in a Brazilian Atlantic forest fragment. Biochemical Genetics, v.48, n.1, p.96-103, 2010.

WHITE, G. M.; BOSHIER, D. H.; POWELL, W. Genetic variation within a fragmented population of Swietenia humilis Zucc. Molecular Ecology, v.8, n.11, p.1899-1909, 1999.

ZIETJIEWICZ, E.; RAFALSKI, A.; LABUDA, D. Genome fingerprinting by simple sequence repeat (SSR)-anchored polymerase chain reaction amplification. Genomics, v.20, n.1, p.176-183, 1994. 